\title{
Unusual Prominent Pulmonary Involvement in a Homozygous PRF1 Gene Variant in a Female Patient
}

\author{
Fahad Alsohime ${ }^{1}$ (I) $\cdot$ Talal Almaghamsi $^{2} \cdot$ Talal A. Basha $^{3} \cdot$ Hosam Alardati $^{4} \cdot$ Malak Alghamdi $^{5} \cdot$ \\ Yousef Mohammed Hawsawi ${ }^{6,7,8}$
}

Received: 28 August 2020 / Accepted: 16 September 2020 / Published online: 28 September 2020

(C) Springer Science+Business Media, LLC, part of Springer Nature 2020

To the editor,

Lymphoproliferative disorders represent a heterogeneous group of monoclonal or polyclonal lymphoid neoplasm that occurs in patients with immune dysfunction. Approximately $90 \%$ of patients with lymphoproliferative disorders have lung involvement, which is usually diagnosed at presentation [1].

Familial hemophagocytic lymphohistiocytosis 2 (FHL) is an autosomal recessive disorder resulting from biallelic mutation in the gene encoding perforin (PRF1; 170280) gene [2]. According to the Histiocyte Society, five out of the following eight criteria are necessary to reach a diagnosis of hemophagocytic lymphohistiocytosis (HLH): fever, enlarged spleen, pancytopenia, hypertriglyceridemia, or hypofibrinogenemia and hemophagocyte in organ biopsy. Additional diagnostic criteria

Fahad Alsohime

falsohime@ksu.edu.sa

1 Pediatric Intensive Care Unit, Department of Pediatrics, King Khalid University Hospital and College of Medicine, King Saud University, PO Box: 7805, Pediatric number 39, Riyadh 11472, Saudi Arabia

2 Department of Pediatrics, King Faisal Specialist Hospital and Research Center, Jeddah, Saudi Arabia

3 Pediatric Allergy-Immunology, Pediatric Department, Faculty of Medicine, University of Jeddah, Jeddah, Kingdom of Saudi Arabia

4 Department of Pathology and Laboratory Medicine, King Faisal Specialist Hospital and Research Center, Jeddah, Saudi Arabia

5 Pediatric Genetics and Metabolic Division, Department of Pediatrics, College of Medicine, King Saud University, Riyadh, Saudi Arabia

6 Research Center, King Faisal Specialist Hospital and Research Center, P.O. Box 40047, Jeddah 21499, Kingdom of Saudi Arabia

7 College of Medicine, Al-Faisal University, P.O. Box 50927, Riyadh 11533, Saudi Arabia

8 Saudi Human Genome Program-Jeddah Satellite Laboratory, Research Center, King Faisal Specialist Hospital and Research Center, P.O. Box 40047, Jeddah 21499, Kingdom of Saudi Arabia include decreased or absent natural cell activity, hyperferritinemia, and elevated CD25 [3]. Previously, it was reported that $13-50 \%$ of adult or pediatric HLH patients had respiratory symptoms; however, no details of the respiratory involvement were presented [4].

Interstitial lung disease (ILD) is one presentation of a variable HLH pulmonary phenotype; it includes granulomatous disease, lymphoid interstitial pneumonia, organizing pneumonia, and lymphoproliferative disorder. The pathophysiology of these complications in HLH patients remains unclear [4].

Lymphocytic interstitial pneumonia is an uncommon lympho-proliferative disorder characterized by infiltration of the interstitial spaces of the lungs by lymphocytes, plasma cells, and other lymphoreticular cells. Radiologically, it is characterized by diffuse ground-glass opacification and thin-walled cysts distributed in a perivascular fashion. Indeed, lung disease is a common and major cause of morbidity and death in these patients [5].

Herein, we report a fatal case of $P R F 1$ mutation and early manifestations of diffuse parenchymal lung disease, as well as interstitial lymphocyte pneumonia without diagnostic features of FHL2, in a female child.

The patient was born to a consanguineous couple of Saudi descent, and she had three healthy siblings. She was delivered at term with unremarkable prenatal and postnatal course. She had a normal growth and development for her age. Apart from minor upper respiratory tract infections, atopic dermatitis, and allergic rhinitis, she was in a good health. Her vaccinations were up-todate, and there was no remarkable family history for recurrent infections or immune deficiency.

Since the age of 4 years, the patient started to develop recurrent chest infections that necessitated frequent admission to the pediatric intensive care unit (PICU). She received multiple courses of empiric antibiotics, and was intubated several times, with an average length of stay for each hospitalization of 10 20 days. Each episode was characterized by fever, cough, tachypnea, and labored breathing with the appearance of new infiltrates on a chest X-ray. A tracheal aspirate culture revealed 
Pseudomonas aeruginosa on different occasions. Viral assays for cytomegalovirus (CMV), Epstein-Barr virus, herpes, and adenovirus were all negative. The repeated chest infections prompted the treating physician to perform a basic immunological workup, including serum immunoglobulins and lymphocyte subsets, which was normal (Table 1). However, the initial lymphocyte proliferation test revealed poor response to phytohemagglutinin (PHA), 13\% compared with control value, she was on steroids at that time. The lymphocyte proliferation test was repeated 6 months after stopping the steroid therapy, and the result of the PHA was normalized, $123 \%$ compared with the control.

Table 1 Laboratory tests results including CBC, liver enzymes, fibrinogen, and immunological workup during last admission

\begin{tabular}{|c|c|c|}
\hline Laboratory test & Normal range & Test result \\
\hline White blood cells & $4.5-13.5 \times 10^{9} / \mu \mathrm{L}$ & $2.95 \times 10^{9} / \mu \mathrm{L}$ \\
\hline Hemoglobin & $115-145 \mathrm{~g} / \mathrm{L}$ & $94 \mathrm{~g} / \mathrm{L}$ \\
\hline Platelets & $140-450 \times 10^{9} / \mu \mathrm{L}$ & $210 \times 10^{9} / \mathrm{L}$ \\
\hline CRP & $0-5 \mathrm{mg} / \mathrm{L}$ & $119.85 \mathrm{mg} / \mathrm{L}$ \\
\hline Aspartate transaminase & $1-60 \mathrm{U} / \mathrm{L}$ & $20 \mathrm{U} / \mathrm{L}$ \\
\hline Alanine transaminase & $16-63 \mathrm{U} / \mathrm{L}$ & $6 \mathrm{U} / \mathrm{L}$ \\
\hline Fibrinogen Level & {$[2.00-4.30]$} & $3.93 \mathrm{~g} / 1$ \\
\hline Triglyceride level & {$[1.7-2.3 \mathrm{mmol} / \mathrm{L}]$} & $3.1 \mathrm{mmol} / \mathrm{L}$ \\
\hline Serum ferritin level & & $264 \mu \mathrm{g} / \mathrm{L}$ \\
\hline WBC flow & $5000-15,000 \mathrm{~mm} 3$ & $5030 \mathrm{~mm} 3$ \\
\hline Lymph flow & $20-45 \%$ & 45 \\
\hline Lymph ABS flow & $1500-4000 \mathrm{~mm} 3$ & 2239 \\
\hline Absolute (Abs) total CD3 & $1600-2700 \mathrm{~mm} 3$ & 1659 \\
\hline Total CD3\% & & 74 \\
\hline Absolute (Abs) helper T CD4 & $1000-1700 \mathrm{~mm} 3$ & 1210 \\
\hline Helper T CD4\% & & 54 \\
\hline $\begin{array}{l}\text { Absolute (Abs) suppressor CD8 T } \\
\text { cells }\end{array}$ & $600-1000 \mathrm{~mm} 3$ & 425 \\
\hline Suppressor CD8 T cells \% & & 19 \\
\hline Absolute (Abs) total B CD 19 & $400-800 \mathrm{~mm} 3$ & 439 \\
\hline Total B CD $19 \%$ & & 20 \\
\hline $\begin{array}{l}\text { Absolute (Abs) total NK CD } 56 \\
\text { and } 16\end{array}$ & $200-400 \mathrm{~mm} 3$ & 125 \\
\hline Total NK CD 56 and $16 \%$ & & 6 \\
\hline CD4/CD8 ratio & $1.30-2.00$ & 2.84 \\
\hline MHC class I\% & & 100 \\
\hline Absolute (Abs) MHC class I mm3 & & 2239 \\
\hline Total MHC class II \% & & 29 \\
\hline $\begin{array}{l}\text { Absolute (Abs) total MHC class II } \\
\text { mm3 }\end{array}$ & & 649 \\
\hline MHC class II CD19 dual +\% & & 20 \\
\hline $\begin{array}{l}\text { Absolute (Abs)MHC class II/ } \\
\text { CD19 dual + }\end{array}$ & & 448 \\
\hline $\operatorname{IgG}$ & $7-16 \mathrm{~g} / \mathrm{L}$ & 6.17 \\
\hline $\operatorname{Ig} \mathrm{A}$ & $0.70-4 \mathrm{~g} / \mathrm{L}$ & 0.92 \\
\hline $\operatorname{IgM}$ & $0.40-2.30 \mathrm{~g} / \mathrm{L}$ & 1.58 \\
\hline
\end{tabular}

Last admission at the age of 7 years was for a chest infection which was complicated by a tension pneumothorax and severe acute respiratory distress syndrome (ARDS) that necessitated the insertion of chest tubes and intubation. Conventional ventilation failed to improve her condition, so high frequency oscillatory ventilation (HFOV) was started but failed to improve her condition. Consequently, a cannula was placed and veno-venous extracorporeal membrane oxygenation (ECMO) was started and maintained for 6 days. She was weaned gradually and ECMO was discontinued. A tracheal aspirate culture was positive for Psudomonas aeruginosa and empiric antibiotics and antifungal medication were prescribed with vancomycin, tazocin, and amphotericin B. The chest X-ray was suggestive of diffuse bilateral air space disease with lower lobe predominance and the CT scan showed interval development of scattered bilateral thinwalled cysts, with no lobe predominance, on a background of extensive airspace disease and signs of bilateral pneumothorax (Fig. 1a, b). Unfortunately, the patient's condition deteriorated with severe ARDS along with multi-organ failure. In spite of full
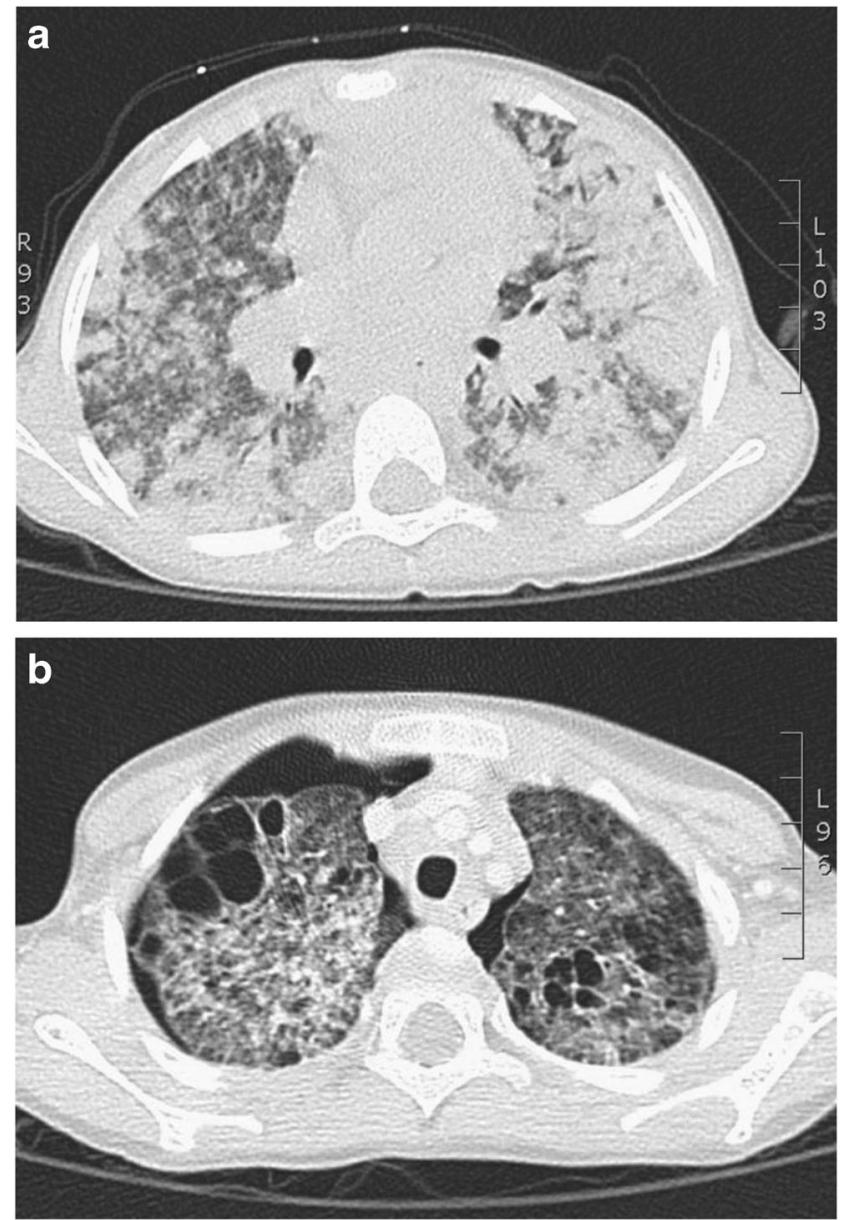

Fig. 1 a Axial chest computed tomography scan in the lung window demonstrates extensive bilateral asymmetric areas of peripheral air space consolidation with associated air bronchograms and b CT scan showed interval development of scattered bilateral thin-walled cysts, with no lobe predominance 
supportive measures and treatment were delivered to the patient including HFOV and ECMO, she died during the admission.

Laboratory investigations are summarized in Table 1. The workup has excluded cystic fibrosis. A broncho-alveolar lavage revealed inflammatory cells, including lymphocytes, alveolar macrophages, and few neutrophils and negative for malignant cells. Also, acid-fast bacilli and fungi staining and viral workup were negative. A lung biopsy was obtained, which showed features suggestive of lymphocytic interstitial pneumonia, with diffuse infiltration of small mature lymphocytes and macrophages associated with alveolar pneumocytes, hyperplasia, and widening of the septa (Fig. 2). The biopsy also showed focally organizing pneumonia but was negative for granulomas, viral inclusions, and necrosis. Immunohistochemistry for $\mathrm{CMV}$, herpes, and adenovirus was negative.

Exome sequence revealed a pathogenic homozygote variant of PRF1 (NM_001083116: c.148G > A; p.V50M), this variant has previously been described as disease causing for FHL2 by Molleran et al. (2004) followed later Sumegi et al., (2014) [6, 7]. This result prompting the investigation of FHL including serum ferritin, triglyceride, and fibrinogen level which were normal.

Because the patient's critical condition, we were unable to complete the HLH diagnostic workup, upon the identification of the $P R F 1$ gene mutation, by performing NK-cell activity testing or measure soluble interleukin-2 receptor levels. Additionally, a bone marrow biopsy was not requested initially because there were no signs of hematopathology to look for increased hemophagocytosis, which is found in $82 \%$ of FHL2 patients.

Okur et al. described a patient carrying homozygous V50M variant, who had a very late-onset with initial presentation of

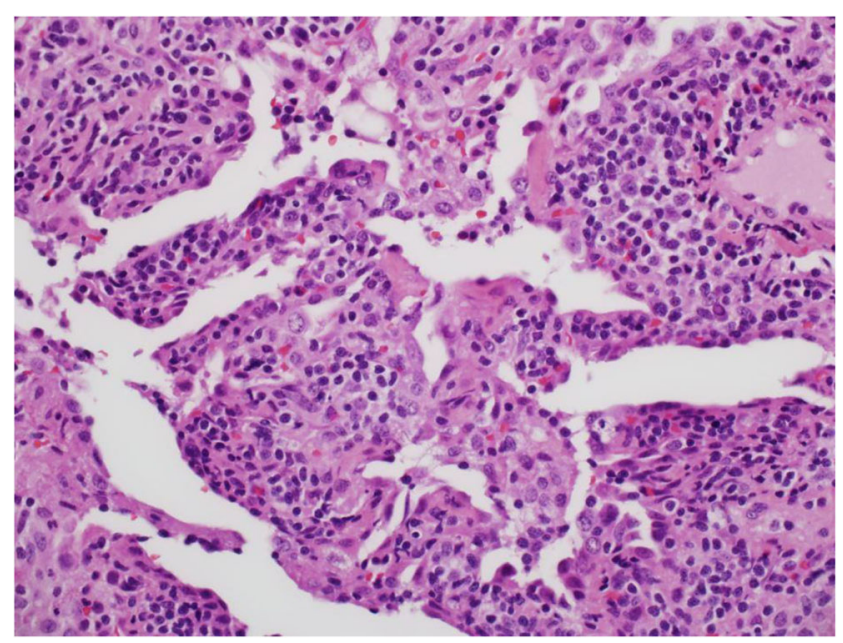

Fig. 2 There is diffuse interstitial lymphocytic infiltrate of small lymphocytes with widening of the alveolar septa and hyperplasia of type 2 pneumocytes. The inflammatory infiltrate also includes macrophages and few neutrophils. (hematoxylin and eosin stain; 400x magnification) central nervous system involvement in the absence of systemic manifestation of FHL2 [8].

Molleran et al. also described a patient with homozygous V50M variant who presented at 7 years of age with the classical FHL2 including hepatosplenomegaly, liver dysfunction, pancytopenia, and hypofibrinogenemia. However, he had a rapid evolving phenotype. This patient showed normal NK function which is exceptional finding in FHL2 patients. The association of the V50M mutation with normal $\mathrm{NK}$ function is a compelling feature that requires further studies [7].

Experiments by Schulert et al. [9] revealed that a disruption of NK cell cytolytic function was probably implicated in the pathophysiology of macrophage activation syndrome (MAS). They identified mutations in PRF1 in approximately $36 \%$ of adults with fatal H1N1 influenza [9].

In studies conducted on children with autoinflammatory diseases, polymorphisms in perforin genes were reported in about one-third of the cases of those who developed MAS [9]. According to previous reports, patients with HLH may have variable clinical manifestations with prominent neurologic or hepatic abnormalities $[10,11]$. However, lung involvement has rarely been evaluated in these patients. In some reports, ARDS is described as the initial manifestation of HLH [12], and patients are typically admitted to the (PICU) due to acute respiratory failure [13]. Until now, however, the mechanism underlying the pathophysiology of acute respiratory failure or its prognostic significance in HLH patients has not been established.

Currently, no incidence or prevalence estimates for lymphocytic interstitial pneumonia (LIP) in children exist. According to a 2017 report from Europe, only three cases of LIP were reported among 346 children with interstitial lung disease [14]. LIP is considered a form of pulmonary lymphoproliferative disease and should be included in the differential diagnosis for childhood interstitial lung disease (ILD). The condition is usually caused or triggered by an underlying autoimmune disease and immunodeficiencies; however, it has also been reported to occur in familial and idiopathic forms $[15,16]$. Additionally, LIP occurs in a considerable proportion of pediatric patients with perinatally acquired HIV who do not receive antiviral therapy $[17,18]$.

Ours is the first individual reported with LIP diagnosed by lung histopathology associated with homozygous pathogenic PRF1 mutations in the absence of clinical characteristics suggestive of FHL-HLH. This case expands the phenotypic spectrum of FHL 2 and provides a pathophysiological link between the PRF1 gene defect and the interstitial lymphocyte pneumonia through impaired NK cell cytotoxicity [19]. We believe that PRF1-related interstitial lung disease is underreported, and it should be suspected in a patient with immunemediated interstitial lung disease to avoid the delayed diagnosis of this potentially curable condition. 
Authors' Contributions All authors meet the International Committee of Medical Journal Editors' authorship criteria.

\section{Compliance with Ethical Standards}

Conflict of Interest The authors declare that they have no conflict of interest.

\section{References}

1. Campo E, Harris NL. WHO classification of tumours of haematopoietic and lymphoid tissues. Revised 4th ed. Lyon: International Agency for Research on Cancer; 2017.

2. Stepp SE, Dufourcq-Lagelouse R, Le Deist F, Bhawan S, Certain S, Mathew PA, et al. Perforin gene defects in familial hemophagocytic lymphohistiocytosis. Science. 1999;286:1957-9. https://doi.org/10. 1126/science.286.5446.1957.

3. Henter JI, Horne A, Arico M, Egeler RM, Filipovich AH, Imashuku S, et al. HLH-2004: diagnostic and therapeutic guidelines for hemophagocytic lymphohistiocytosis. Pediatr Blood Cancer. 2007;48(2):124-31.

4. Seguin A, Galicier L, Boutboul D, Lemiale V, Azoulay E. Pulmonary involvement in patients with hemophagocytic lymphohistiocytosis. Chest. 2016;149:1294-301. https://doi.org/ 10.1016/j.chest.2015.11.004.

5. Kim R, Meyer KC. Therapies for interstitial lung disease: past, present and future. Ther Adv Respir Dis. 2008;2:319-38. https:// doi.org/10.1177/1753465808096948.

6. Sumegi J, Nestheide SV, Barnes MG, Villanueva J, Zhang K, Grom AA, et al. Gene-expression signatures differ between different clinical forms of familial hemophagocytic lymphohistiocytosis. Blood. 2013;121(7):e14-24. https://doi.org/10.1182/blood-201205-425769.

7. Molleran Lee, Villanueva J, Sumegi J, Zhang K, Kogawa K, Davis $\mathrm{J}$, et al. Characterisation of diverse PRF1 mutations leading to decreased natural killer cell activity in North American families with haemophagocytic lymphohistiocytosis. J Med Genet. 2004;41: 137-44. https://doi.org/10.1136/jmg.2003.011528.

8. Okur H, Balta G, Akarsu N, Oner A, Patiroglu T, Bay A, et al. Clinical and molecular aspects of Turkish familial hemophagocytic lymphohistiocytosis patients with perforin mutations. Leuk Res. 2008;32(6):972-5. https://doi.org/10.1016/j.leukres.2007.11.033.

9. Schulert GS, Zhang M, Fall N, Husami A, Kissell D, Hanosh A, et al. Whole-exome sequencing reveals mutations in genes linked to hemophagocytic lymphohistiocytosis and macrophage activation syndrome in fatal cases of H1N1 influenza. J Infect Dis. 2016;213:1180-8. https://doi.org/10.1093/infdis/jiv550.

10. de Kerguenec C, Hillaire S, Molinié V, Gardin C, Degott C, Erlinger S, et al. Hepatic manifestations of hemophagocytic syndrome: a study of 30 cases. Am J Gastroenterol. 2001;96:852-7. https://doi.org/10.1111/j.1572-0241.2001.03632.x.

11. Henter JI, Nennesmo I. Neuropathologic findings and neurologic symptoms in twenty-three children with hemophagocytic lymphohistiocytosis. J Pediatr. 1997;130:358-65. https://doi.org/ 10.1016/s0022-3476(97)70196-3.

12. Nishikawa T, Okamoto Y, Tanabe T, Shinkoda Y, Kodama Y, Kakihana $Y$, et al. Acute respiratory distress syndrome as an initial presentation of hemophagocytic lymphohistiocytosis after induction therapy for acute myeloid leukemia. Pediatr Hematol Oncol. 2011;28:244-8. https://doi.org/10.3109/08880018.2010.514038.

13. Buyse S, Teixeira L, Galicier L, Mariotte E, Lemiale V, Seguin A, et al. Critical care management of patients with hemophagocytic lymphohistiocytosis. Intensive Care Med. 2010;36:1695-702. https://doi.org/10.1007/s00134-010-1936-z.

14. Griese M, Seidl E, Hengst M, Reu S, Rock H, Anthony G, et al. International management platform for children's interstitial lung disease (chILD-EU). Thorax. 2018;73:231-9. https://doi.org/10. 1136/thoraxjnl-2017-210519.

15. Rogers BB, Browning I, Rosenblatt H, McClain K, Kemp J, Glasser LL, et al. A familial lymphoproliferative disorder presenting with primary pulmonary manifestations. Am Rev Respir Dis. 1992;145:203-8. https://doi.org/10.1164/ajrccm/145.1.203.

16. Franchi LM, Chin TW, Nussbaum E, Riker J, Robert M, Talbert WM. Familial pulmonary nodular lymphoid hyperplasia. J Pediatr. 1992;121:89-92. https://doi.org/10.1016/s0022-3476(05)82550-8.

17. Church JA, Isaacs H, Saxon A, Keens TG, Richards W. Lymphoid interstitial pneumonitis and hypogammaglobulinemia in children. Am Rev Respir Dis. 1981;124:491-6. https://doi.org/10.1164/arrd. 1981.124.4.491.

18. Andiman W, Shearer W. Lymphoid interstitial pneumonitis. In: Pizzo P, Wilfert C, editors. Pediatr. AIDS Chall. HIV Infect. Infants Child. Adolesc. 3rd ed. Baltimore: Lippincott Williams \& Wilkins; 1998. p. 323.

19. House IG, Thia K, Brennan AJ, Tothill R, Dobrovic A, Yeh WZ, et al. Heterozygosity for the common perforin mutation, p.A91V, impairs the cytotoxicity of primary natural killer cells from healthy individuals. Immunol Cell Biol. 2015;93:575-80. https://doi.org/ 10.1038/icb.2015.1.

Publisher's Note Springer Nature remains neutral with regard to jurisdictional claims in published maps and institutional affiliations. 